Article

\title{
Emotional and Behavioral Difficulties, Communication, Intelligence, and Reasoning in Children with Hearing Difficulties
}

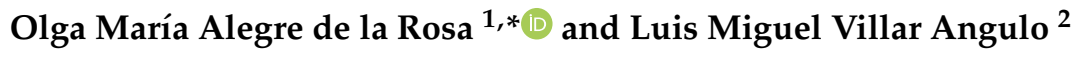 \\ 1 Department of Didactics and Educational Research, University of La Laguna, 38200 San Cristóbal de La \\ Laguna, Santa Cruz de Tenerife, Canary Islands, Spain \\ 2 Department of Didactics and Educational Organization, University of Seville, 41004 Sevilla, Spain \\ * Correspondence: oalegre@ull.edu.es; Tel.: +34-92-231-9026 (ext. 38204)
}

Received: 14 July 2019; Accepted: 29 August 2019; Published: 4 September 2019

check for updates

\begin{abstract}
This study aims to investigate whether emotional and behavioral difficulties (EBD) differ between children with cochlear implants (CIs) or hearing aids (HAs), according to multi-informant ratings. Methods: A battery of psychological measures (e.g., Strengths and Difficulties Questionnaire (SDQ), Illinois Test of Psycholinguistic Abilities (ITPA), Peabody Image Vocabulary Test (PPVT), and Raven Progressive Matrices Test (RPM), was administered to children with CIs or HAs. The study involved 187 children with CIs, 113 children with HAs, 176 fathers and mothers, and 300 schoolteachers. Results: Significant disagreements were found between children, parents, and schoolteachers with regard to SDQ ratings. Total SDQ difficulties score correlated poorly with other outcomes (e.g., total ITPA, final PPVT, and final RPM). Regression linear analyses showed six socio-demographic and linguistic covariates that significantly predicted children's total SDQ difficulties score. Conclusion: Several independent variables were found to be associated with children's total EBD scores. This article highlights the importance of providing professionals with sufficient training so that they are knowledgeable about the procedures they are to use to support children with EBD (e.g., developing and implementing instructional approaches for school students with EBD).
\end{abstract}

Keywords: cochlear implant; hearing aid; family; teacher; SDQ

\section{Introduction}

This study attempts to detect individual differences between children who use two types of hearing assistive devices. The sensory information perceived by children with hearing assistive devices is essential to overcome the delay they exhibit in the quality of spoken language. So, children using hearing assistive devices have psychological difficulties related to their speech perception (Henner, Novogrodsky, Reis, \& Hoffmeister [1]. From an educational perspective, the administration of psychological tests concerns researchers because children with insufficient linguistic development need to thoroughly understand test instructions. In fact, class teachers and speech-language pathologists are not the only educational agents that remedy the linguistic weaknesses of children with hearing assistive devices. Families also provide fluency in the primary oral communication, which sustains the basic perceptual scheme of the child's future cognitive development. As Luft [2] (p. 2) has written: "All families function as the de facto language development interventionists for their children."

The mental health of children with hearing loss may be impacted by difficulties in communication (Stevenson, Kreppner, Pimperton, Worsfold, \& Kennedy [3]. Moreover, Edwards, Hill, and Mahon [4] reported that the concept of communication and independence in children is problematic. Overall, the 
notion denotes students' perceptual difficulties, or ascribes knowledge dependency and disability to children who use cochlear implants (CIs) or hearing aids (HAs). The equality or difference of children with CIs or HAs affects their perceptions of educational achievement, personal health, emotional well-being, and emotional and behavioral difficulties (EBD). To date, there has been no attempt to give a quantitative assessment of the magnitude of differences in the rates of EBD in general in children with CIs or HAs in the Canary Islands.

\subsection{Measurement of Individual Differences}

This paper focuses specifically on the Strengths and Difficulties Questionnaire (SDQ) because it provides "well-validated sub-scale scores, with equivalent ratings based on parent, teacher and self-report which can be analyzed separately but in parallel" [3] (p. 478). Spanish analyses also have demonstrated the structure and reliability of SDQ $[5,6]$.

The questionnaire SDQ is unique in that it derives essential understandings of students' interpersonal relations. The SDQ is conceived as an instrument to perform the screening of positive socialization behavior and the psychopathology of 3-16-year-old children. Many health clinics now use SDQ as part of the initial assessment of children with hearing loss getting parents, schoolteachers, and students to complete questionnaires prior to the first clinical assessment. As such, SDQ measures are useful for investigators to demonstrate, scientifically, the impact of EBD of children using hearing assistive devices on their instructional needs.

In general, children with CIs are perceptually affected, and consequently, parents and schoolteachers are obliged to acquire and demonstrate new communication and language competencies. In fact, Huber and Kipman [7] (p. 152) used SDQ to assess the mental health condition of 32 adolescents with CIs and 212 typical hearing peers. From their study, an important conclusion was drawn: "Teachers rated those with CIs as having more peer problems, and more 'total' problems" (p. 152). On the contrary, Wong et al. [8] (p. 15) found that "children with CIs or HAs did not show significant emotional or behavioral difficulties compared with norms (SDQ)." Furthermore, educators' challenges have been to develop strategies to activate the social skills of children with CIs. Similarly, Wong et al. [9] compared families' and educators' perceptions of the social behavior of children with CIs.

The existing literature comprises conflicting reports concerning the cognitive capacity of children after implantation of hearing assistive devices. The specific evaluation of all or some of the psycholinguistic skills of children with CIs or HAs attracted the interest of some researchers when the Illinois Test of Psycholinguistic Abilities (ITPA) was used. Specifically, ITPA is a criterion measure to determine the psycholinguistic training of educators, providing a wide variety of diagnosed children's cognitive abilities [10]. For example, Alegre, Rodríguez, Villar, and Pérez [11] administered the ITPA and the Peabody Image Vocabulary Test (PPVT) and found that the children's age at the time of early cochlear implantation was a good predictor of adequate linguistic development.

Although children with CIs or HAs are able to solve complex instructional issues cognitively, the PPVT establishes how children's age at the time of cochlear implantation is an essential predictor of speech and language outcomes in students with CIs [12]. Later studies have examined the extent to which children with unilateral and mild bilateral hearing loss are at risk of social skills difficulties, compared with typical hearing children and children with moderate to severe hearing loss [13]. After all, PPVT test reports predictors of language development in children with CIs $[14,15]$.

Children with CIs-from the school curriculum perspective-experience reduced rates in school learning processes. They also display slower understandings of spoken language. Nevertheless, the identification of students with hearing loss who are academically proficient is an issue of great concern in educational theory and research. The use of the Raven Progressive Matrices Test (RPM) estimates the abstract reasoning fluency of children with CIs or HAs. Even though the test has a large number of items, researchers have reduced Raven's test size [16] without losing their predictive validity, demonstrating "that items are largely measurement invariant" [17]. In retrospect, other scholars have reported on the limitations of the linguistic and cognitive processing of children with CIs compared 
to their peers who hear complex semantic tasks [18]. For example, reports have demonstrated that children with CIs have an altered perception of music due to their auditory difficulties. However, Shirvani et al. [19] (pp. 475-476) used the Iranian version of 32 Raven elements to compare three groups of children (normal hearing, bimodal adjustment, and profound hearing loss and unilateral $\mathrm{CIs}$ ) and found that "a weak perception of musical emotions in children with unilateral CIs can lead to weakness in the communicative message of music" (pp. 475-476).

\subsection{Significance and Purposes of the Current Study}

Parents and schoolteachers of children with CIs or HAs deal with many challenges in making decisions regarding diagnostic teaching, creating informed opinions about children's abstract reasoning, and promoting the development of spoken or sign language in children with hearing difficulties $[9,20]$.

The aims of this study were:

1. To explore multiple inter-rater (i.e., class teachers-speech-language pathologists, children-school professionals, children-parents, and class teachers-parents) concordance correlation coefficients for SDQ data. Authors calculated agreement reports between students, parents, and schoolteachers on EBD of children with CIs or HAs to give homogeneity and consistency to scores [21].

2. To uncover the functional relationships of EBD and psycholinguistic abilities, image vocabulary, and abstract reasoning of children with CIs or HAs [22].

To predict the children's total SDQ score using the children's psychological variables (e.g., ITPA, PPVT, and RPM). Furthermore, we aimed to predict the children's total SDQ score by influences from other aggregated multi-informants' socio-demographic predictors: Student-level covariates (e.g., gender; hearing device; individualized curriculum adaptation (ICA) instructional program; chronological and implantation age), school-level covariates (e.g., grade, school speech therapy (number of hours), tutor, and speech-language pathologist experience (number of years), family-level covariates (e.g., gender, studies, parents' age (father and mother), and home communication), and geographical location-level covariate (e.g., administrative province of residence) [15] (Sarchet et al., 2014).

\section{Methods}

\section{Participants}

All eligible children in the Canary Islands were recruited to the study. The study cohort consisted of children with CIs $(n=187)$ and HAs $(n=113)$. They had access to the same hearing service provider (Canary Health Service) before they turned three years of age. One hundred and thirty-seven children were recruited from the island of Tenerife and 163 from the island of Gran Canary. The chronological ages of the children were between 6-9 years $(n=104), 10-12$ years $(n=88)$, and $13-16$ years $(n=108)$. They attended inclusive school centers. One hundred and nineteen followed the ICA instructional program, while 181 enrolled in the regular curriculum of their typical peers. Etiological causes were excluded from the study because of lacking information.

All parents and proxy families provided informed written consent for administering questionnaires and tests to each child with CIs or HAs. Further, ethical and legal disposition approval for the present study was attained from the Clinical Research Ethics Committee (C.E.I.C.) of the Canary Insular Maternal and Child University Hospital. The role of family-center care was essential for children's communication [23] (Ching et al., 2018). Therefore, authors included parental education and family labor status as latent variables that might predict children's strengths and psycho-educational problems [24] (Porter, Sladen, Ampah, Rothpletz, \& Bess, 2013). Thus, fathers $(n=87)$ and mothers $(n=89)$ had primary education degrees, and they were working (parents $n=230$, mothers $n=213$ ). Fathers contributed data in the cycle of 41-50 years old $(n=143)$, between $31-40$ years old $(n=95)$, more than 50 years $(n=55)$, and between $20-30$ years $(n=7)$. Mothers' age contributed data between $41-50$ years old $(n=143)$, between $31-40$ years old $(n=95)$, more than 50 years old $(n=55)$, and between $20-30$ years old $(n=15)$. 
On one hand, other authors have substantiated fathers' active role in oral communication with their children, noting parents who utilized verbal communication $(n=215)$, compared to those who employed only signs $(n=28)$ or were bilingual $(n=57)$. On the other hand, there was ambivalent data about the role played by school professionals who had been in contact with children with CIs or HAs. While class teachers display adequate attitudes towards the inclusion of children with hearing loss in regular school classrooms, school professionals need to prepare the teachers to deal with cochlear implant technology and other auditory issues $[25,26]$.

There are generally a greater number of female teachers (speech-language pathologists $(n=249)$ and class teachers $(n=227))$ compared to male teachers (speech-language pathologists $(n=51)$ and class teachers $(n=73))$. The average age of speech-language pathologists was $50-59$ years $(n=171)$, and that of the class teachers was 60 or more $(n=150)$. On average, both types of school educators had professional experience of 10 years or more: Speech-language pathologists $(n=193)$ and class teachers $(n=185)$.

\section{Materials}

\subsection{Strengths and Difficulties Questionnaire (SDQ)}

Goodman $[27,28]$ designed and developed the SDQ. All versions of the SDQ request about 25 attributes, some positive and some negative. SDQ is comprised of four subscales: Emotional problems, behavioral problems, problems with peers, and hyperactivity, which produce subscale scores that can be summed to produce a "total difficulties" score and a fifth separate prosocial scale score. The SDQ is an instrument to perform the screening of the positive behavior of socialization and the psychopathology of 4-16-year-old children and adolescents. The same 25 items are included in the questionnaires for parents or teachers of children to complete them. According to the developer, the SDQ is available in more than 77 language versions. The results of the factor analysis replicated by researchers from different countries validated the SDQ structure [5,29]. Cronbach's alpha values are different in this research according to the groups studied: Children with CIs or HAs (0.789), speech-language pathologists (0.725), class teachers (0.616), and families (fathers and mothers) (0.759), which represented an adequate reliability value [30].

\subsection{Illinois Test of Psycholinguistic Abilities (ITPA)}

Before the translated version of the ITPA into Spanish, 68 studies had adopted this instrument between 1968 and 1974 to investigate children's abilities [10,31]. It is composed of 10 subtests, for each of the following functions: Listening comprehension, visual comprehension, visual-motor sequential memory, auditory association, auditory sequential memory, visual association, visual integration, verbal expression, and grammatical integration. It allows the detection, prediction, and diagnosis of possible errors or difficulties in the child's communication process. Some researchers have applied the whole instrument to children with CIs [32] or specific subtests for predicting individual differences in peer acceptance and friendship formation among children with specific language impairments [22]. Cronbach's alpha value for internal consistency for this study is 0.852 , which represents a reasonable reliability coefficient [30].

\subsection{Peabody. Image Vocabulary Test (PPVT)}

This interactive test [33] has two alternative forms (A and B) of a receptive vocabulary assessment. Each type includes 228 elements, equally distributed across 19 item-sets. Each item-set contains 12 elements of increasing difficulty. The administration time is limited to 10-15-min by applying the sets according to the child's age or skill level. Children point to one out of four images that best represents the meaning of a verbally presented stimulus word. The average reliability coefficient for this test, based on the normative sample, was 0.89 [14]. However, the reported Cronbach's alpha coefficient for this study was 0.641 , which is considered a questionable coefficient [30]. 


\subsection{Raven Progressive Matrices Test (RPM)}

This instrument [34,35] has been distributed to deaf or hard of hearing children for the last 50 years [1]. It comprises 60 items that measure abstract reasoning, in which children are required to select the missing fragment from an incomplete plan. The reported Cronbach's alpha coefficient for this study was 0.713 , which seems an acceptable coefficient [30].

\section{Procedure}

Authors obtained written consent for the child's participation in the study from each father, mother, or both. Parents, class teachers, speech-language pathologists, and children with CIs or HAs completed the SDQ and a socio-demographic background questionnaire either at home or school. The socio-demographic questionnaire for parents and class teachers sought information about gender, the age of hearing loss of children, communication mode, geographical location, and educational setting. Further, the family's economic situation was measured using the parental employment status. Parents and the Gran Canary Hospital provided data on age of children in the first auditory fitting, the degree of hearing loss, type of hearing device, and age of cochlear implantation. Members of the research team (school psychologists) administered the ITPA, PPVT, and RPM tests in a quiet schoolroom or the child's clinical setting. Each testing session lasted a morning with certain pauses. Collaboration between class teachers and speech-language pathologists supported children's communication skills in the ICA instructional program [36].

\section{Statistical Analysis}

First, descriptive statistics, which included means and standard deviations, were calculated. All statistical analyses selected an alpha level of 0.05 . Second, the agreement rates between children and school professionals as well as school professionals and families were computed using Cohen's kappa coefficient on SDQ subscales. Third, Pearson correlation coefficients examined the strength of the linear relationship between the responses of children with hearing assistive devices on the SDQ subscales, the total ITPA scores, and the final PPVT and RPM scores. Next, a separate Pearson correlation was performed for the class teachers and children with hearing assistive devices on the total SDQ and ITPA scores along with the final PPVT and RPM scores. The size of the effects for this context was $\mathrm{d}=0.2$ which would be considered a "small" effect size, $0.5 \mathrm{a}$ "medium" effect size, and 0.8 a "large" effect size [37]. Lastly, multiple regression analyses were conducted to examine the predictive power of independent variables in the SDQ total score. Socio-demographic factors and other psychological factors (e.g., total ITPA score, final PPVT and RPM scores, and a combination of SDQ subscale scores of families and class teachers) were the independent variables. All analyses were performed with SPSS statistics version 21 .

\section{Results}

\subsection{Examination of Inter-Rater Reliability of the SDQ Subscales with Cohen's Kappa}

According to the study's first aim, a mild agreement was found between speech-language pathologists and class teachers on the SDQ subscales, when they scored on the EBD of children with CIs or HAs. Results also disclosed a moderate agreement between both school professionals on the behavioral problems subscale for HAs $(k=-0.405, p<0.001)$.

Furthermore, a mild agreement was observed between school professionals and children on the total SDQ and subscales outcomes of children with HAs $(k=0.415, p<0.001)$. Likewise, a moderate agreement appeared between children and speech-language pathologists, although this was exclusively attributed to the behavioral problems subscale of children with HAs $(k=0.415, p<0.001)$. Similarly, a moderate agreement was revealed on the emotional problems subscale of children with CIs or class teachers $(k=0.410, p<0.001)$. The poor agreements that can be observed in the other SDQ subscales 
have led researchers to think about the class teachers' limited awareness of the EBD of children with hearing loss.

\subsection{Examination the Relationship between Five Subscales SDQ and ITPA, PPVT y RPM}

We found small associations between children's self-report SDQ subscale scores (e.g., emotional problems slightly correlated with behavioral problems $(r=0.325, p<0.001)$, which were not statistically correlated with Problems with peers $(r=-0.122, p<0.05)$. (See Table 1 ).

This result implied that when emotional problems increased, problems with peers decreased in a constant proportion. Correlation analyses indicated that behavioral problems demonstrated significant correlations with problems with peers $(r=0.391, p<0.001)$ and hyperactivity $(r=0.260, p<0.001)$, which was not statistically correlated with prosocial behavior $(r=-0.298, p<0.001)$. This score showed that when behavioral problems increased, prosocial behavior decreased in a constant proportion. Moreover, correlation coefficients indicated a statistically significant relationship between hyperactivity and problems with peers $(r=0.445, p<0.001)$, but hyperactivity was not statistically correlated with prosocial behavior $(r=-0.291, p<0.001)$. This outcome denoted that when hyperactivity increased, prosocial behavior diminished in a constant proportion. Finally, problems with peers was not statistically correlated with prosocial behavior $(r=-0.432, p<0.001)$. This result suggested that when problems with peers increased, prosocial behavior declined constantly.

Furthermore, a statistically significant, small, and positive correlation was observed between children's SDQ subscale scores along with the child's total ITPA score (total ITPA score is the mean of all subscales) $(r=0.115, p<0.05)$ and final RPM score $(r=0.115, p<0.05)$. In the same vein, findings revealed that children's total ITPA score was small and correlated with children's final RPM score $(r=0.115, p<0.05)$ and SDQ subscale scores (e.g., behavioral problems, $r=0.163, p<0.001$, and hyperactivity, $r=0.177, p<0.001)$. Further, correlations between children's final PPVT score with SDQ subscale scores (e.g., behavioral problems, $r=0.118, p<0.05$, and prosocial behavior, $r=-0.141$, $p<0.05)$ were significant and small.

\subsection{Children's Problems, Psycholinguistic Abilities, and Cognitive Capacities}

As the second aim of this study claimed, children's total SDQ scores were small and significantly correlated with speech-language pathologists $(r=0.250, p<0.001)$ and class teachers $(r=0.247$, $p<0.001)$. Links between children's problems and receptive vocabulary were accepted. Correlation analyses indicated that speech-language pathologists' total SDQ score was not statistically correlated with children's final PPVT score $(r=-0.113, p<0.05)$. This result indicated that when speech-language pathologists' total SDQ score increased, final PPVT score decreased constantly. Moreover, correlation analyses demonstrated that speech-language pathologists were significantly correlated with class teachers $(r=0.258, p<0.001)$ on the total SDQ score.

As indicated in Table 2, ITPA subtests significantly correlated among themselves (e.g., auditory reception with verbal expression $(r=0.616, p<0.001)$, auditory reception with auditory sequential memory $(r=0.632, p<0.001)$, and auditory reception with grammatic closure $(r=0.581, p<0.001)$. These correlations represented an association between two levels of organization of increasing complexity. 
Table 1. Correlations between the five Strengths and Difficulties Questionnaire (SDQ) subscales and Illinois Test of Psycholinguistic Abilities (ITPA), Peabody Image Vocabulary Test (PPVT), and Raven Progressive Matrices Test (RPM) for children.

\begin{tabular}{|c|c|c|c|c|c|c|c|c|}
\hline & ITPA & PPVT & RPM & Emotional Problems & Behavioral Problems & Hyperactivity & Problems with Peers & Prosocial Behavior \\
\hline ITPA & 1.000 & & & & & & & \\
\hline PPVT & $\begin{array}{c}-0.073 \\
0.206\end{array}$ & 1.000 & & & & & & \\
\hline RPM & $\begin{array}{l}0.115^{*} \\
0.046\end{array}$ & $\begin{array}{l}0.077 \\
0.186\end{array}$ & 1.000 & & & & & \\
\hline $\begin{array}{l}\text { Emotional } \\
\text { problems }\end{array}$ & $\begin{array}{c}-0.049 \\
0.394\end{array}$ & $\begin{array}{c}-0.053 \\
0.358\end{array}$ & $\begin{array}{l}0.016 \\
0.781\end{array}$ & 1.000 & & & & \\
\hline $\begin{array}{l}\text { Behavioral } \\
\text { problems }\end{array}$ & $\begin{array}{c}-0.163^{* *} \\
0.005\end{array}$ & $\begin{array}{c}0.118^{*} \\
0.041\end{array}$ & $\begin{array}{c}-0.061 \\
0.292\end{array}$ & $\begin{array}{c}0.325^{* *} \\
0.000\end{array}$ & 1.000 & & & \\
\hline Hyperactivity & $\begin{array}{c}-0.177^{* *} \\
0.002\end{array}$ & $\begin{array}{l}0.091 \\
0.116\end{array}$ & $\begin{array}{c}-0.011 \\
0.843\end{array}$ & $\begin{array}{c}-0.108 \\
0.062\end{array}$ & $\begin{array}{c}0.260^{* *} \\
0.000\end{array}$ & 1.000 & & \\
\hline $\begin{array}{l}\text { Problems with } \\
\text { peers }\end{array}$ & $\begin{array}{c}-0.200 * * \\
0.001\end{array}$ & $\begin{array}{l}0.108 \\
0.061\end{array}$ & $\begin{array}{l}0.001 \\
0.985\end{array}$ & $\begin{array}{c}-0.122 \text { * } \\
0.034\end{array}$ & $\begin{array}{c}0.391 * * \\
0.000\end{array}$ & $\begin{array}{c}0.445^{* *} \\
0.000\end{array}$ & 1.000 & \\
\hline $\begin{array}{l}\text { Prosocial } \\
\text { behavior }\end{array}$ & $\begin{array}{l}0.094 \\
0.103\end{array}$ & $\begin{array}{c}-0.141 \text { * } \\
0.015\end{array}$ & $\begin{array}{l}0.017 \\
0.772\end{array}$ & $\begin{array}{l}0.098 \\
0.090\end{array}$ & $\begin{array}{c}-0.298^{* *} \\
0.000\end{array}$ & $\begin{array}{c}-0.291^{* *} \\
0.000\end{array}$ & $\begin{array}{c}-0.432 * * \\
0.000\end{array}$ & 1.000 \\
\hline
\end{tabular}

** Correlation coefficients significant at the 0.001 level (bilateral), * Correlation coefficients significant at the 0.05 level (bilateral). 
Table 2. Correlations between the SDQ and ITPA, PPVT (Peabody), and RPM (Raven) for teachers and children with hearing aids.

\begin{tabular}{|c|c|c|c|c|c|c|}
\hline & $\begin{array}{c}\text { SDQ Total. Speech-Language } \\
\text { Pathologist }\end{array}$ & SDQ Total. Tutor & $\begin{array}{l}\text { SDQ Total. Children } \\
\text { with Hearing Aids }\end{array}$ & $\begin{array}{l}\text { Total ITPA } \\
\text { Score. } \\
\text { Children with } \\
\text { Hearing Aids }\end{array}$ & $\begin{array}{l}\text { PPVT Final Score. } \\
\text { Children with } \\
\text { Hearing Aids }\end{array}$ & $\begin{array}{l}\text { RPM Final } \\
\text { Score. } \\
\text { Children with } \\
\text { Hearing Aids }\end{array}$ \\
\hline $\begin{array}{l}\text { SDQ Total. } \\
\text { Speech-language } \\
\text { pathologist }\end{array}$ & 1.000 & & & & & \\
\hline $\begin{array}{l}\text { SDQ Total. } \\
\text { Tutor }\end{array}$ & $0.258^{* *}$ & 1.000 & & & & \\
\hline $\begin{array}{l}\text { SDQ Total. Children with } \\
\text { hearing aids }\end{array}$ & $0.250^{* *}$ & $0.247^{* *}$ & 1.000 & & & \\
\hline $\begin{array}{c}\text { Total ITPA Score. } \\
\text { Children with hearing aids }\end{array}$ & 0.053 & 0.037 & $0.115^{*}$ & 1.000 & & \\
\hline $\begin{array}{c}\text { PPVT Final Score. } \\
\text { Children with hearing aids }\end{array}$ & -0.113 * & 0.050 & -0.062 & -0.073 & 1.000 & \\
\hline $\begin{array}{c}\text { RPM Final Score. } \\
\text { Children with hearing aids }\end{array}$ & 0.032 & 0.053 & 0.053 & $0.115 *$ & 0.077 & 1.000 \\
\hline
\end{tabular}

${ }^{*}$ Correlation coefficients significant at the 0.05 level (bilateral), ${ }^{* *}$ Correlation coefficients significant at the 0.001 level (bilateral). 


\subsection{Children's Problems Related to Children's Aptitudes and Parents' and School Covariates}

This study's third aim was to explain the relationship between the independent (predictor) and dependent (target) variables. Consequently, a linear regression was analyzed by looking for an R-square as close to 1 that indicated a perfect linear fit. Authors employed the method of multiple linear regression analysis and fulfilled the assumptions of linearity, independence, normality, homoscedasticity, and non-collinearity to guarantee the validity of the predictive value of the selected array of variables.

The method of least squares was chosen (Table 3). The Pearson correlation coefficient was 0.751, and the goodness of fit was calculated following the coefficient of determination R-square, whose values ranged between -1 and 1 . Hence, the corrected value of $\mathrm{R}$-square $=0.551$ predicted $55.1 \%$ of the variance (corrected effect of the sample and independent variables). The typical estimation error (square root of the unexplained variance) turned out to be 0.468 . The analysis of variance (ANOVA) showed whether the variance explained by the regression was significantly different (and superior) to the unexplained variance. The model was $\mathrm{F}=42.431, p<0.001$, which revealed that the associated probability according to the expectations of the null hypothesis was less than 0.001 . This finding led the authors to reject this hypothesis and assume that there was a real effect of these variables on the children's total SDQ score.

Table 3. Regression analysis of the socio-demographic variables as predictors of children's total SDQ score.

\begin{tabular}{|c|c|c|c|c|c|c|c|}
\hline Target & $\mathbf{R}$ & $\mathrm{R}^{2}$ & $F$ & Explained Variance & Socio-Demographic Predictors & $\beta$ & $t$ \\
\hline $\begin{array}{c}\text { Children's } \\
\text { total SDQ } \\
\text { score }\end{array}$ & 0.751 & 0.564 & $42.431^{* * *}$ & $55.10 \%$ & $\begin{array}{c}\text { Hearing device } \\
\text { Geographical location } \\
\text { ICA } \\
\text { Mothers' age } \\
\text { Children's chronological age }\end{array}$ & $\begin{array}{c}1.155 \\
-0.268 \\
0.23 \\
-0.1504 \\
0.078\end{array}$ & $\begin{array}{c}10.511^{* * *} \\
-3.278^{* * *} \\
3.019^{* *} \\
-2.789^{* *} \\
2.006^{*}\end{array}$ \\
\hline
\end{tabular}

${ }^{*} p<0.05,{ }^{* *} p<0.010,{ }^{* * *} p<0.001$.

Finally, the authors reported the regression coefficients for the chosen model, and the constant was expressed first, followed by the slope. The model suggested that the independent variables (e.g., hearing assistive devices, geographical location, ACI, mothers' age, and children's chronological age) revealed statistical significance. In this model, hearing assistive device (CIs/HAs) obtained the highest coefficient $(t=10.511, p<0.000)$.

The results of the regression analysis-ITPA subscales, PPVT, and RPM dimensions-are shown in Table 4 , where ITPA subscales explained $42.6 \%$ of the variance of the children's total SDQ score. The automatic level auditory-vocal had considerable weight in the EBD score of the children's total SDQ score, specifically, the scales of visual sequential memory, auditory sequential memory, and grammatic closure. The representative level viso-motor in verbal expression scale and the representative level viso-motor in auditory reception scale also had a significant weight. The obtained F-value was 8.594. According to the expectations of the null hypothesis, its associated probability was less than 0.001 . Therefore, this hypothesis was rejected. Consequently, these variables could affect the children's total SDQ score. 
Table 4. Summary of stepwise regressions ITPA outcomes predicting children's total SDQ score.

\begin{tabular}{|c|c|c|c|c|c|c|c|}
\hline Model & $\mathbf{R}$ & $\mathbf{R}^{2}$ & $F$ & Explained Variance & ITPAVariables & $\beta$ & $t$ \\
\hline \multirow{5}{*}{$\begin{array}{l}\text { Children's } \\
\text { total SDQ } \\
\text { score }\end{array}$} & \multirow{5}{*}{0.426} & \multirow{5}{*}{0.181} & \multirow{5}{*}{$8.594^{* * *}$} & \multirow{5}{*}{$42,6 \%$} & $\begin{array}{l}\text { Automatic Level Auditory- Motor } \\
\text { Sequential Viso-Motor Memory }\end{array}$ & 0.022 & $4.502^{* * *}$ \\
\hline & & & & & $\begin{array}{c}\text { Automatic Level Auditory-Vocal } \\
\text { Auditory Sequential Auditory Memory }\end{array}$ & -0.014 & $-2.934^{* *}$ \\
\hline & & & & & $\begin{array}{l}\text { Automatic Level Auditory-Vocal } \\
\text { Grammatic Closure }\end{array}$ & 0.015 & $3.781^{* * *}$ \\
\hline & & & & & $\begin{array}{l}\text { Representative Level Auditory-Vocal } \\
\text { Verbal Expression }\end{array}$ & -0.014 & $-2.846^{* *}$ \\
\hline & & & & & $\begin{array}{l}\text { Representative Level Viso-Motor } \\
\text { Visual Closure }\end{array}$ & -0.014 & $-2.683^{* *}$ \\
\hline
\end{tabular}

Overall, we stated that the total SDQ score is clearly influenced by integrated habits, such as memory and remote learning, which produced an automatic chain of responses. Similarly, the automatic level auditory-vocal might influence the visual sequential memory $(t=4.502, p<0.001)$.

\section{Discussion}

Researchers and educators use multiple sources of information to assess the EBD of children with hearing loss and appraise the variability in perceptions and judgments of subjects belonging to school and family contexts [21].

\subsection{Measuring Inter-Rater Agreement of SDQ Subscale Ratings}

The present study aims first to investigate patterns of agreement among class teachers, families, and children across SDQ subscales. Accurately, we use Cohen's kappa coefficient metric of categorical measures to study the correspondence between informants. The different sources (families, children, and class teachers) rate the EBD of children with CIs or HAs in a discrepant manner (e.g., rs often in discordance among informants' ratings 0.00-0.20) [38].

However, there are pairs of informants, which cause different correspondence agreements in the Cohen's kappa coefficients (e.g., mother-father, father-son with CIs, father-class teacher, and class teacher-child with CIs). The categorical covariates (e.g., child age and pairs of class teachers who observe children over different periods) account for some of the variability among the effects. Child evaluations tend to produce low to moderate levels of correspondence among informants. However, we notice mild levels of correspondence occurring when informants have relatively more significant opportunities to observe (e.g., speech-language pathologists perceive conduct problems in children with HAs) within the same school class context (e.g., class teachers observe emotional symptoms of children with CIs).

On the contrary, mothers have a unique position to observe children in a wide variety of situations and for long periods compared to other informants such as class teachers and peers. The little or no agreement between children and parents of this study may be due to the inability of the children. Furthermore, family refusal can be considered as a psychological issue rather than children misbehavior. Although parents' speech encourages children's vocabulary progress, families have limited knowledge about children's interpersonal relations with other peers [39].

The relationship between behavior, communication, receptive vocabulary, and abstract reasoning of children with hearing devices.

Regarding the second aim of the study, we hypothesize a correlation between children's EBD, psycholinguistic abilities, and cognitive aptitudes. In deaf and hearing loss education, diagnostic-prescriptive teaching refers to the launch of the ICA instructional program for students 
with learning difficulties. As a rule, learning problems involve many uncovered factors. We have found that the scores on the problems with peers subscale are significantly and negatively associated with prosocial behavior. This means that friendship quality develops while problems with peers decreases [22]. Further, participants who rate themselves higher on prosocial behavior inversely evaluate behavioral problems, hyperactivity, and problems with peers.

We assume that this result is to be expected because of the subsample of adolescents, whose prosocial involvement is characterized as a positive youth development construct. The correlations between SDQ subscales in children with hearing loss appear low and unconnected. These correlation outcomes also indicate differences between the SDQ subscales depending on distal factors (e.g., administering the same questionnaire to students in different school grades from different provinces by different parents and class teachers). Furthermore, the results hint at similarities between children with CIs and those with HAs before the assistive device implantation. This is due to the lack of baseline data, which other studies have outlined [32].

In this study, the correlations between ITPA and SDQ scores exhibit a low relationship. In any case, it has previously been reported that ITPA maintains low correlations with other tests [31]. The auditory reception and verbal expression subtests are to be used in the selection of children for placement in ICA instructional programs. Further, these representational subtests are significantly correlated with the RPM [31].

Speech-language pathologists and class teachers correlate on SDQ total score, although the size of the effect is small. Moreover, both school professionals associate with children using hearing assistive devices, but the size of the effect is equally small. In children with hearing implants, the need for continuous observation of children and the complexity for identifying children's communication and social problems makes speech-language pathologist and class teacher-based diagnosis difficult [1]. Data reports that children with CIs or HAs misunderstand words from content areas of the PPVT.

\subsection{Predictors of Children's Behavior Problems and Difficulties}

\subsubsection{Hearing Assistive Devices}

This study shows that children with CIs or HAs disagree in some SDQ subscale ratings. However, other studies have not found differences between children with early bilateral CIs and "matched hearing controls" in an SDQ subscale (i.e., prosocial behavior) [40].

\subsubsection{Geographical Location}

The regression model highlights some socio-demographic predictors of total SDQ scores that need additional comments. This research has revealed that the province is a predictor of children's psychosocial problems and difficulties, as it happened in other studies [41,42]. The Gran Canary model of service delivery is unique (e.g., the Unit of Hearing loss, where children are fitted with implants, which is enriched by closer technical and personnel resources in comparison to the Tenerife service). Therefore, it would be of interest to replicate the study in other Spanish provinces where a similar or different model is employed.

\subsubsection{ICA}

The ICA instructional program as a form of compensatory instructional design and inclusive practice makes the total SDQ outcome in a classroom environment. The route of the ICA intensity taken by each school learner depends on the initial diagnosis of the children's ITPA abilities in each "significant instructional response" (e.g., memory and remote learning or those integrated abilities) [36]. 


\subsubsection{Mothers' Age}

This study emphasizes mothers' age as an important resource for solving problems of children with hearing assistive devices. Future studies could exemplify the benefits of maternal education or mother-to-mother support for children's social and emotional health-related quality of life [43].

\subsubsection{Children's Chronological Age}

Child's age of chronological implantation influences psychosocial problems and difficulties [18]. Future research should center on the functional hearing children have from birth until they receive their implants, when oral communication, lexis, and grammar develop [44].

\subsubsection{ITPA Subscale}

The regression analysis of this study reveals that the factor ITPA automatic level auditory-vocal predicts total SDQ score of children with CIs; that is, children's ability to obtain meaning from orally presented material, and evaluates their semantic knowledge that causes children's problems and difficulties. Therefore, auditory-verbal therapy demands a high level of interaction between speech-language pathologists, parents, and class children [42].

\subsection{Limitations}

The present study has some limitations. The results of this study are only typical of the majority of the population of children with CIs or HAs of the Canary Islands without multiple disabilities. Further, those children's peer relation, classroom learning environment, home environment, auditory threshold grouping of children, and student cognitive processes contribute to their psychosocial development, and the present study has not assessed these factors.

\subsection{Educational Implications}

Speech-language pathologist and class teacher training programs ought to be implemented at university, for diagnosing children's psychosocial difficulties and designing school aptitude-treatment instructional systems [1]. This study also suggests the need for mentoring parents of children with hearing loss, due to the low or no agreement between children with CIs or HAs and their parents in assessing children's psychological difficulties [45]. We particularly highlight the conclusion of Isarin et al.'s [20] research on the importance of child and family-centered case management topics (e.g., care, facilities, and services).

\section{Conclusions}

The findings from this study show divergence in the assessment of children's psychological problem outcomes, among the following groups: Children with CIs or HAs, fathers and mothers, and speech-language pathologists and class teachers. Although the study found evidence that SQD and ITPA did not correlate, from the data collected, we reported significant correlations among ITPA subscales. This study has entered independent variables not generally included in regression analysis and has identified new predictive factors of outcomes in children with hearing loss (hearing assistive device, geographical location, ICA, mothers' age, children's chronological age, and ITPA subtest). Overall, this study has significantly expanded the body of knowledge (personal, environmental, curricular, and familiar) regarding children with hearing loss in the Canary Islands.

Author Contributions: Conceptualization, writing—original draft, O.M.A.R.; data curation, methodology, formal analysis, O.M.A.R.; writing-review and editing, L.M.V.A.

Funding: This research was funded by CajaCanarias Foundation grant number CSOCSEDO3.

Conflicts of Interest: The authors declare no conflict of interest. 


\section{References}

1. Henner, J.; Novogrodsky, R.; Reis, J.; Hoffmeister, R. Recent Issues in the use of Signed Language Assessments for Diagnosis of Language Disorders in Signing Deaf and Hard of Hearing children. J. Deaf Stud. Deaf Educ. 2018, 23, 307-316. [CrossRef] [PubMed]

2. Luft, P. What Is Different about Deaf Education? The Effects of Child and Family Factors on Educational Services. J. Spec. Educ. 2016, 51, 27-37. [CrossRef]

3. Stevenson, J.; Kreppner, J.; Pimperton, H.; Worsfold, S.; Kennedy, C. Emotional and behavioural difficulties in children and adolescents with hearing impairment: A systematic review and meta-analysis. Eur. Child Adolesc. Psychiatry 2015, 24, 477-496. [CrossRef] [PubMed]

4. Edwards, L.; Hill, T.; Mahon, M. Quality of life in children and adolescents with cochlear implants and additional needs. Int. J. Pediatr. Otorhinolaryngol. 2012, 76, 851-857. [CrossRef] [PubMed]

5. Ortuño-Sierra, J.; Fonseca-Pedrero, E.; Inchausti, F.; Sastre i Riba, S. Evaluación de dificultades emocionales y comportamentales en población infanto-juvenil: El Cuestionario de Capacidades y Dificultades (SDQ). Pap. Psicól. 2016, 37, 14-26.

6. Rodríguez-Hernández, P.J.; Betancort, M.; Ramírez-Santana, G.M.; García, R.; Sanz-Alvarez, E.J.; De las Cuevas-Castresana, C. Puntos de corte de la versión española del Cuestionario de Cualidades y Dificultades (SDQ). Rev. Psiquiatr. Infanto Juv. 2014, 3, 23-29.

7. Huber, M.; Kipman, U. The mental health of deaf adolescents with cochlear implants compared to their hearing peers. Int. J. Audiol. 2011, 50, 146-154. [CrossRef]

8. Wong, C.L.; Ching, T.Y.C.; Cupples, L.; Button, L.; Leigh, G.; Marnane, V.; Whitfield, J.; Gunnourie, M.; Martin, L. Psychosocial Development in 5-Year-Old Children with Hearing Loss Using Hearing Aids or Cochlear Implants. Trends Hear. 2017, 21. [CrossRef]

9. Wong, C.L.; Ching, T.Y.C.; Cupples, L.; Leigh, G.; Marnane, V.; Button, L.; Martin, L.; Whitfield, J.; Gunnourie, M. Comparing parent and teacher ratings of emotional and behavioural difficulties in 5-year old children who are deaf or hard-of-hearing. Deaf. Educ. Int. 2018, 1-24. [CrossRef]

10. Kirk, S.A.; McCarthy, J.J.; Kirk, W.D. Illinois Test of Psycholinguistic Abilities; TEA: Madrid, Spain, 2001.

11. Alegre, O.M.; Rodríguez, M.C.; Villar, L.M.; Pérez, D. Evaluación de la Eficacia del Implante Coclear en Función de la Edad de Implantación. Eur. Sci. J. 2016, 12, 42-51. [CrossRef]

12. Connor, C.M.; Craig, H.K.; Raudenbush, S.W.; Heavner, K.; Zwolan, T.A. The age at which young children receive cochlear implants and their vocabulary and speech production growth: Is there an added value for early implantation? Ear Hear. 2006, 27, 628-644. [CrossRef] [PubMed]

13. Laugen, N.J.; Jacobsen, K.H.; Rieffe, C.; Wichstrøm, L. Social skills in preschool children with unilateral and mild bilateral hearing loss. Deaf. Educ. Int. 2017, 19, 54-62. [CrossRef]

14. Sarant, J.; Harris, D.; Bennet, L.; Bant, S. Bilateral Versus Unilateral Cochlear Implants in Children: A Study of Spoken Language Outcomes. Ear Hear. 2014, 35, 396-409. [CrossRef] [PubMed]

15. Sarchet, T.; Marschark, M.; Borgna, G.; Convertino, C.; Sapere, P.; Dirmyer, R. Vocabulary Knowledge of Deaf and Hearing Postsecondary Students. J. Postsecond. Educ. Disabil. 2014, 27, 161-178. [PubMed]

16. Bilker, W.B.; Hansen, J.A.; Brensinger, C.M.; Richard, J.; Gur, R.E.; Gur, R.C. Development of Abbreviated Nine-Item Forms of the Raven's Standard Progressive Matrices Test. Assessment 2012, 19, 354-369. [CrossRef] [PubMed]

17. Lúcio, P.S.; Cogo-Moreira, H.; Puglisi, M.; Polanczyk, G.V.; Little, T.D. Psychometric Investigation of the Raven's Colored Progressive Matrices Test in a Sample of Preschool Children. Assessment 2017, 9. [CrossRef]

18. Asker-Arnason, L.; Ibertsson, T.; Wass, M.; Wengelin, A.; Sahlen, B. Picture-Elicited Written Narratives, Process and Product, in 18 Children with Cochlear Implants. Commun. Disord. Q. 2010, 31, $195-212$. [CrossRef]

19. Shirvani, S.; Jafari, Z.; Zarandi, M.M.; Jalaie, S.; Mohagheghi, H.; Tale, M.R. Emotional Perception of Music in Children with Bimodal Fitting and Unilateral Cochlear Implant. Ann. Otol. Rhinol. Laryngol. 2016, 125, 470-477. [CrossRef]

20. Isarin, J.; Zadelhoff, I.; Wolters-Leermakers, N.; Speksnijder-Bregman, M.; Hannink, M.; Knoors, H. A World of Difference. Parental Perspectives on Cochlear Implantation in Deaf Children with Additional Disabilities. Deaf. Educ. Int. 2015, 17, 219-230. [CrossRef] 
21. Gresham, F.M.; Elliott, S.N.; Metallo, S.; Byrd, S.; Wilson, E.; Cassidy, K. Cross-informant agreement of children's social-emotional skills: An investigation of ratings by teachers, parents, and students from a nationally representative sample. Psychol. Sch. 2018, 55, 208-223. [CrossRef]

22. Durkin, K.; Conti-Ramsden, G. Language, social behavior, and the quality of friendships in adolescents with and without a history of specific language impairment. Child Dev. 2007, 78, 1441-1457. [CrossRef] [PubMed]

23. Ching, T.Y.C.; Scarinci, N.; Marnane, V.; Sjahalam-King, J.; Button, L.; Whitfield, J. Factors influencing parents' decisions about communication choices during early education of their child with hearing loss: A qualitative study. Deaf. Educ. Int. 2018, 20, 154-181. [CrossRef] [PubMed]

24. Porter, H.; Sladen, D.P.; Ampah, S.B.; Rothpletz, A.; Bess, F.H. Developmental outcomes in early school-age children with minimal hearing loss. Am. J. Audiol. 2013, 22, 263-270. [CrossRef]

25. Compton, M.V.; Tucker, D.A.; Flynn, P.F. Preparation and Perceptions of Speech-Language Pathologists Working with Children with Cochlear Implants. Commun. Disord. Q. 2009, 30, 142-154. [CrossRef]

26. Eriks-Brophy, A.; Whittingham, J. Teachers' perceptions of the inclusion of children with hearing loss in general education settings. Am. Ann. Deaf 2013, 158, 63-97. [CrossRef]

27. Goodman, R. The strengths and difficulties questionnaire: A research note. J. Child Psychol. Psychiatry 1997, 38, 581-586. [CrossRef] [PubMed]

28. Goodman, R. Psychometric properties of the Strengths and Difficulties Questionnaire. J. Am. Acad. Child Adolesc. Psychiatry 2001, 40, 1337-1345. [CrossRef] [PubMed]

29. Stevanovic, D.; Urbán, R.; Atilola, O.; Vostanis, P.; Balhara, Y.; Avicenna, M.; Kandemir, H.; Knez, R.; Franic, T.; Petrov, P. Does the Strengths and Difficulties Questionnaire-Self report yield invariant measurements across different nations? Data from the International Child Mental Health Study Group. Epidemiol. Psychiatr. Sci. 2015, 24, 323-334. [CrossRef]

30. George, D.; Mallery, M. Using SPSS for Windows Step by Step: A Simple Guide and Reference; Allyn \& Bacon: Boston, MA, USA, 2003.

31. Kirk, S.A.; Elkins, J. Summaries of Research on the Revised Illinois Test of Psycholinguistics; Final Report, ERIC (ED115024); Arizona University: Tucson, AR, USA, 1974.

32. Jiménez, M.S.; Pino, M.J.; Herruzo, J. A comparative study of speech development between deaf children with cochlear implants who have been educated with spoken or spoken+ sign language. Int. J. Pediatr. Otorhinolaryngol. 2009, 73, 109-114. [CrossRef]

33. Dunn, L.M.; Dunn, D.M. The Peabody Picture Vocabulary Test, 4th ed.; NCS Pearson, Inc.: Bloomington, MN, USA, 2007.

34. Raven, J. The Raven Progressive Matrices: A review of national norming studies and ethnic and socioeconomic variation within the United States. J. Educ. Meas. 1989, 26, 1-16. [CrossRef]

35. Raven, J. The Raven's Progressive Matrices: Change and stability over culture and time. Cogn. Psychol. 2000, 41, 1-48. [CrossRef] [PubMed]

36. Fuchs, D.; Fuchs, L.S. Rethinking Service Delivery for Students with Significant Learning Problems: Developing and Implementing Intensive Instruction. Remedial Spec. Educ. 2015, 36, 105-111. [CrossRef]

37. Peng, C.-Y.P.; Chen, L.-T. Beyond Cohen's $d$ : Alternative Effect Size Measures for Between-Subject Designs. J. Exp. Educ. 2014, 82, 22-50. [CrossRef]

38. De Los Reyes, A.; Kazdin, A. Informant discrepancies in assessment of childhood psychopathology: A critical review. Psychol. Bull. 2005, 131, 483-509. [CrossRef] [PubMed]

39. McAloney-Kocaman, K.; McPherson, K. Factor Structure and Reliability of the Parent-Informant Strengths and Difficulties Questionnaire in a Scottish Preschool Sample. Early Educ. Dev. 2017, 28, 368-376. [CrossRef]

40. Sarant, J.; Harris, D.; Galvin, K.L.; Bennet, L.A.; Canagasabey, M.; Busby, P. Social Development in Children with Early Cochlear Implants: Normative Comparisons and Predictive Factors, Including Bilateral Implantation. Ear Hear. 2018, 39, 770-782. [CrossRef] [PubMed]

41. Hyde, M.; Punch, R.; Grimbeek, P. Factors predicting functional outcomes of cochlear implants in children. Cochlear Implant. Int. 2011, 12, 94-104. [CrossRef] [PubMed]

42. Neuss, D. The ecological transition to auditory-verbal therapy: Experiences of parents whose children use cochlear implants. Volta Rev. 2006, 106, 195-222.

43. Henderson, R.J.; Johnson, A.; Moodie, S. Parent-to-Parent Support for Parents with Children Who Are Deaf or Hard of Hearing: A Conceptual Framework. Am. J. Audiol. 2014, 23, 437-448. [CrossRef] 
44. De Hoog, B.E.; Langereis, M.C.; Weerdenburg, M.V.; Keuning, J.; Knoors, H.; Verhoeven, L. Auditory and verbal memory predictors of spoken language skills in children with cochlear implants. Res. Dev. Disabil. 2016, 57, 112-124. [CrossRef]

45. Archbold, S.; Sach, T.; O'neill, C.; Lutman, M.; Gregory, S. Outcomes from Cochlear Implantation for Child and Family: Parental Perspectives. Deaf. Educ. Int. 2008, 10, 120-142. [CrossRef] 